\title{
VIABILIDADE ECONÔMICA PARA A PRODUÇÃO DE ALFACE NO SISTEMA HIDROPÔNICO EM COLOMBO, REGIÃO METROPOLITANA DE CURITIBA, PR
}

\author{
ECONOMIC VIABILITY FOR LETTUCE PRODUCTION ON HIDROPONIC \\ SYSTEM AT COLOMBO, METROPOLITAN REGION OF CURITIBA, PR
}

\author{
Eduardo Teixeira da SILVA ${ }^{1}$ - \\ Fabiano SCHWONKA ${ }^{2}$
}

\begin{abstract}
RESUMO
A hidroponia garante, de certa maneira, um mercado paralelo aos produtos ofertados convencionalmente, onde se articula maior qualidade e confiança de consumo, favorecendo o bemestar do consumidor. O objetivo principal desse trabalho foi mostrar a viabilidade da prática hidropônica na produção de alface crespa, bem como apresentar aos produtores resultados que evidenciem vantagens em relação ao custo-benefício, para a localidade de Colombo, região metropolitana de Curitiba, expressiva produtora de hortaliças do Estado do Paraná. O levantamento foi conduzido na Chácara Acqua Vita, durante o ano de 1998. Foram utilizadas cinco estufas com produção mensal de 3.600 cabeças de alface em cada uma, ao preço de $R \$ 0,60$ a unidade. Foram estudadas as seguintes variáveis: total de custos (custo fixo + variável); produção total/estufa/mês; receita total; lucro/estufa/mês; preço obtido por cabeça de alface vendida; custo por cabeça de alface produzida; lucro por cabeça de alface produzida; lucro para cinco estufas de produção/mês; remuneração do empresário; total de benefícios/mês; total de investimentos; lucro anual para cinco estufas; e pagamento do investimento. Observou-se maior taxa de custo voltado para o transporte, aquisição e montagem das estufas sendo, porém, esses dois pontos os manipuláveis com a finalidade de diminuir os custos e aumentar o lucro final. Mesmo considerando os altos custos de produção, evidenciou-se que cerca de $50 \%$ do valor recebido pelo agricultor é definido como lucro.
\end{abstract}

Palavras-chave: Lactuca sativa, cultivo protegido, viabilidade econômica.

\begin{abstract}
Hydroponic production guarantees a parallel market to that for conventionally-produced vegetables, because consumers presume that hydroponic products are of higher quality and more beneficial to health than conventionally-produced products. The main objective of this work was to show the viability of hydroponic cultivation in the production of curly lettuce and to demonstrate to producers the clear advantages of hydroponic production from a cost-benefit perspective, especially when compared to the current conventional production practices used in Colombo, one of the major vegetable producing regions in the greater metropolitan area of Curitiba, the capital of the State of Paraná, Brasil. The cultivation was done under real cultivation conditions, on the Chácara Acqua Vita. Five greenhouses were used, giving a monthly production of 3,600 heads of lettuce, with a sales price of $R \$ 0.60$ per head. They were studied the following variables: total of costs (fixed cost + variable); production total/greenhouses/monthly; total revenue; profit/greenhouses/monthly; price obtained by heads of sold lettuce; cost for head of produced lettuce; profit for head produced lettuce; profit for five production/month greenhouses; the entrepreneur's remuneration; total of profit/month; total of investments; profit annual for five greenhouses; payment of the investment. The major contributors to the production cost were the cost of transport to the market and the cost of construction of the greenhouses. However, these two variables can be manipulated to increase profits. Despite the greater production costs, it was evidenced that about $50 \%$ of the price received by the producer was definided as the profit.
\end{abstract}

Key words: Lactuca sativa, hidroponic cultivation, economic viability.

\footnotetext{
${ }^{1}$ Engenheiro Agrícola, Doutor, Universidade Federal do Paraná, Departamento de Solos e Engenharia Agrícola, Professor, Rua dos Funcionários, 1540, CEP 80035-050, Curitiba, PR. E-mail: eduardo@agrarias.ufpr.br Đ Autor para correspondência.

2 Engenheiro Agrônomo, Universidade Federal do Paraná, Departamento de Solos e Engenharia Agrícola, Estagiário.
} 


\section{INTRODUÇÃO}

A hidroponia, termo derivado de duas palavras de origem grega, hidro = água e ponia = trabalho, técnica que, segundo Furlani (1998) [3], está se desenvolvendo rapidamente como meio de produção vegetal, especialmente de hortaliças sob cultivo protegido. A hidroponia é uma técnica alternativa de cultivo protegido, na qual o solo é substituído por uma solução aquosa, contendo apenas os elementos minerais necessários aos vegetais. A hidroponia é uma ciência jovem, sendo utilizada como atividade comercial há apenas quarenta anos (Resh, 1997 [6]). Nesse curto período de tempo adaptou-se a diversas situações, desde o cultivo no ar, em estufas altamente especializadas passando por submarinos atômicos para obter verduras frescas para sua tripulação, porém, pode ser utilizada por países em desenvolvimento para prover a produção intensiva de alimentos em áreas limitadas.

De acordo com Martins e Silva (1997) [5], a população da cidade de Curitiba é de aproximadamente 1.500 .000 habitantes, logo o consumo diário de alface pode ser de 45.000 cabeças por dia. Curitiba possui hoje, entre pequenos, médios e grandes comércios (supermercados, quitandas, varejões, feiras, etc), algo em torno de 950 pontos de venda, sendo a média entre estes de quarenta cabeças por dia, de modo que tem-se uma oferta de 38.000 cabeças por dia. De acordo com o sindicato dos hotéis, restaurantes, bares e similares de Curitiba, a média de refeições está em torno de 100.000 refeições por dia, sendo que cada pessoa consome em média duas folhas de alface por refeição. Como uma cabeça de alface possui entre 20 e 22 folhas tem-se, então, nesse caso, um consumo de 9.500 cabeças por dia.

Os custos de implantação de um sistema hidropônico para alface, segundo Faquin et al. (1996) [2] e Martins e Silva (1997) [5] são bastante variáveis, especialmente em função da estrutura utilizada. Geralmente, esse custo é estimado em 15 a 20 mil Reais para uma estrutura capaz de produzir dez mil cabeças por mês. O custo de produção tem sido estimado ao redor de dez centavos de Real por planta, sem considerar a amortização do investimento inicial. De acordo com Furlani (1998) [3], os custos são variáveis, em função da estrutura a ser utilizada e, geralmente, os custos de instalação estão em torno de $\mathrm{R} \$ 5,00$ a $\mathrm{R} \$ 20,00$ por metro quadrado. $O$ autor relata ainda, que de acordo com informações de diversos produtores o custo de produção de uma planta de alface tem oscilado entre 10 e 15 centavos de Real.

Bliska Júnior e Honório (1996) [1], recomendam que se deve agir racionalmente para se ter idéia do investimento necessário para a implantação de um sistema de produção hidropônica. Os autores dizem que, para uma produção de duzentas plantas de alface por dia, utilizando um espaçamento de plantio de $0,25 \mathrm{~m}$ x $0,25 \mathrm{~m}$, levando-se em conta que o ciclo da alface é de 53 dias, pode-se obter um lucro de $\mathrm{R} \$ 76,00$ por dia. Ao longo do ano, considerando o valor de um mês empregado como capital de giro e o período de onze meses para o cálculo, tem-se lucro total de $\mathrm{R} \$ 20.900,00$ no ano; ou seja, a amortização dos recursos investidos pode ser feita em três a quatro meses.

Esse trabalho teve como objetivo principal analisar a viabilidade da prática hidropônica na produção de alface crespa, cultivar Verônica, bem como apresentar aos produtores, resultados que evidenciem vantagens em relação ao custobenefício, para a região de Colombo, área da região metropolitana de Curitiba, expressiva produtora de hortaliças do Estado do Paraná.

\section{METODOLOGIA}

O levantamento foi conduzido na Chácara Acqua Vita, do Engenheiro Agrônomo Paulo César Wolff, localizada no município de Colombo, PR, região metropolitana de Curitiba, produtora, em sua maioria, de hortaliças, durante o ano de 1998. O município está localizado na latitude $25^{\circ} 20^{\prime} \mathrm{S}$ e longitude $49^{\circ} 14^{\prime} \mathrm{W}$ com clima, segundo a classificação de Köeppen, Cfb, subtropical super úmido, com verões frescos e geadas severas, demasiadamente freqüentes (médias de cinco por ano), sem estação seca. A temperatura média anual é de $16,5^{\circ} \mathrm{C}$, sendo a do mês mais quente e mais frio de $20,1^{\circ} \mathrm{C}$ e $12,8^{\circ} \mathrm{C}$ respectivamente. O mês mais chuvoso é janeiro e o menos chuvoso é agosto.

A área total da propriedade considerada tem 2 ha e o custo inicial de aquisição da mesma foi de $\mathrm{R} \$ 20.000,00$. O proprietário tem um total de cinco estufas do tipo arco, com estrutura em pilares préfabricados e arcos de ferro galvanizado, nas dimensões de 7,0 $\mathrm{m} \times 50,0 \mathrm{~m}$ e pé-direito de $3,2 \mathrm{~m}$. A cobertura das estufas foi feita com plástico de polietileno aditivado com espessura de 0,0002 m. As bancadas de sustentação foram feitas com madeira e as calhas de produção com canos de PVC branco de $0,10 \mathrm{~m}$, cortados ao meio no sentido longitudinal, forradas com filme plástico e recobertas com isopor, com orifícios de $0,05 \mathrm{~m}$ de diâmetro espaçados a $0,20 \mathrm{~m}$ entre plantas.

A produção de alface crespa mensal média ultrapassa 3.600 cabeças por estufa, utilizando a técnica de cultivo em fluxo laminar de nutrientes (NFT - Nutrient Film Technique), produção essa que dependia do manejo adequado e conseqüente minimização de perdas; sendo o manejo realizado por monitoramento diário do $\mathrm{pH}$ (mantido entre 5,5 e $6,5)$, da condutividade elétrica da solução nutritiva, utilizando condutivímetro portátil (mantida entre 2,0 e $\left.2,5 \mathrm{mS} \mathrm{cm}^{-1}\right)$, do nível de oxigênio $\left(\mathrm{O}_{2}\right)$ da solução nutritiva pela aeração artificial (recirculação da água dentro do reservatório), da temperatura por termômetros de máximas e mínimas instalados nas estufas. No sistema NFT utilizado, a circulação da solução nutritiva foi realizada por um período de quinze minutos com quinze minutos de intervalo, desde o amanhecer até $\mathrm{o}$ anoitecer e, durante a 
noite, a solução circulava por quinze minutos com intervalos de dois a três controlados por um temporizador.

Os cálculos necessários para a obtenção dos custos de depreciação, juros, seguros e conservação/reparos foram obtidos em entrevista feita com o proprietário e acompanhamento diário na propriedade, durante o ano de 1998. Pesquisas de preços de mercado dos itens que compõem os custos fixos e variáveis foram feitas em Colombo, $\mathrm{PR}$ e, em seguida, procedeu-se à execução da análise de custos e benefícios da propriedade em questão, de acordo com Hoffmann et al. (1987)[4]. O preço obtido na venda para o consumidor foi de $\mathrm{R} \$ 0,50$ e a renda bruta $\mathrm{R} \$ 1.800,00$ por mês.

Diante dos aspectos relacionados a estrutura da propriedade foi descrita da maneira que se segue de acordo com Hoffmann et al. (1987) [4]: a) Capital Agrário Fundiário

- terra nua; e

- melhoramentos fundiários (construções: escritório, galpão, casa para caseiro e estufas; estrada vicinal; cercas; sistemas de irrigação; poço artesiano; luz elétrica; água em rede; e telefone celular rural).

b) Capital Agrário de Exploração

- fixo: máquinas (moto-bombas), temporizador, implementos (pulverizador), circuito de encanamentos, bancadas de madeira, caixas de armazenamento da solução nutritiva, arcos para estrutura das estufas, plástico de polietileno, sombrites, utilitários (veículo próprio); e

- circulante: Insumos, despesas gerais e serviços, combustíveis e lubrificantes e salários (contratados).

c) Trabalho (remuneração):

- próprio (empresário); e

- contratados (permanente e temporário)

QUADRO 1 - Custos fixos de uma estufa de produção, Colombo, PR, 1998

\begin{tabular}{|c|c|c|c|c|}
\hline Descrição & Valor $(\mathrm{R} \$)$ & Depreciação $(\mathrm{R} \$)$ & Juros $(R \$)$ & Seguro $(R \$)$ \\
\hline Estufa (pilares e arcos) & $2.000,00$ & 180,00 & 66,00 & 20,00 \\
\hline Estufa (bancadas de madeira) & 500,00 & 45,00 & 16,50 & 5,00 \\
\hline Estufa (parte hidráulica) & 500,00 & 64,28 & 16,50 & 5,00 \\
\hline Estufa (plástico polietileno) & 500,00 & 150,00 & 16,50 & 5,00 \\
\hline Uma moto bomba & 220,00 & 39,60 & 7,26 & 2,20 \\
\hline Pulverizador manual / costal & 45,00 & 4,05 & 1,49 & 0,45 \\
\hline Caixa Reservatório $7.000 \mathrm{~L}$ & 250,00 & 22,50 & 8,25 & 2,50 \\
\hline Terra 2 ha & $20.000,00$ & - & 600,00 & - \\
\hline Casa do Caseiro $60 \mathrm{~m}^{2}$ & $3.000,00$ & 135,00 & 99,00 & 15,00 \\
\hline Barracão $180 \mathrm{~m}^{2}$ & $10.000,00$ & 257,15 & 330,00 & 50,00 \\
\hline Total (estufa/ano) & $17.015,00$ & 897,58 & $1.161,50$ & 105,15 \\
\hline Total (estufa/mês) & - & 74,80 & 96,80 & 8,76 \\
\hline Mão-de-Obra & & & & \\
\hline Dois trabalhadores fixos & 100,00 & - & - & - \\
\hline Remuneração empresária & 200,00 & - & - & - \\
\hline Impostos e taxas $3 \%$ ano & 20,00 & - & - & - \\
\hline Subtotal 1 & 350,00 & 74,80 & 96,80 & 8,76 \\
\hline Subtotal Geral 1 & \multicolumn{4}{|c|}{530,36} \\
\hline
\end{tabular}

\section{RESULTADOS}

Os resultados são expostos nos Quadros 1 e 2, apresentando os custos fixos e os variáveis, junto com análise e a interpretação dos mesmos. Os valores de insumos e despesas gerais foram obtidos por entrevista, onde o produtor considerou valores intermediários de custo os insumos e despesas gerais. Devido ao andamento do negócio o produtor já tem em mente quanto vai gastar de insumos durante um mês de produção por estufa. A embalagem custa, para cada cabeça de alface, $\mathrm{R} \$ 0,0225$, e para 4.000 cabeças o custo é de $\mathrm{R} \$ 90,00$. Os defensivos são aplicados duas vezes por ciclo, totalizando um valor de $\mathrm{R} \$ 10,00$, em ambas as aplicações (um inseticida, um fungicida e um acaricida). A soma de insumos e despesas gerais são para quarenta e cinco dias de produção, após a entrada das mudas compradas. 
QUADRO 2 - Custos variáveis de uma estufa de produção, Colombo, PR, 1998

\begin{tabular}{|c|c|c|c|}
\hline \multicolumn{3}{|c|}{ Transporte externo } & $\mathrm{R} \$$ \\
\hline \multicolumn{3}{|c|}{ - Combustíveis } & 316,00 \\
\hline \multicolumn{3}{|c|}{ - Lubrificantes } & 20,00 \\
\hline \multicolumn{4}{|c|}{ Conservação e reparos } \\
\hline \multicolumn{4}{|c|}{ Máquinas e implementos ( $4 \%$ ao ano) } \\
\hline Descrição & Valor inicial $(\mathrm{R} \$)$ & Conservação/reparos anual (R\$) & Conservação/reparos mensal (R\$) \\
\hline Veículo Kombi & $4.000,00$ & 160,00 & 13,33 \\
\hline Estufa geral & $3.000,00$ & 120,00 & 10,00 \\
\hline Pulverizador & 60,00 & 2,40 & 0,20 \\
\hline \multicolumn{4}{|c|}{ Benfeitorias ( $2 \%$ ao ano ) } \\
\hline Descrição & Valor inicial $(\mathrm{R} \$)$ & Conservação/reparos anual (R\$) & Conservação/reparos mensal (R\$) \\
\hline Barracão & $10.000,00$ & 200,00 & 16,67 \\
\hline Casa & $3.000,00$ & 60,00 & 5,00 \\
\hline \multicolumn{4}{|c|}{ Insumos (valor a cada 45 dias) } \\
\hline \multicolumn{3}{|l|}{ Mudas } & 30,80 \\
\hline \multicolumn{3}{|l|}{ Fertilizantes } & 70,00 \\
\hline \multicolumn{3}{|l|}{ Defensivos } & 10,00 \\
\hline \multicolumn{3}{|l|}{ Embalagem } & 90,00 \\
\hline \multicolumn{4}{|c|}{ Despesas gerais } \\
\hline \multicolumn{3}{|l|}{ Energia elétrica } & 100,00 \\
\hline \multicolumn{3}{|c|}{ Alimentação, emergências. } & 25,00 \\
\hline \multicolumn{3}{|c|}{ Outros (aluguel de serviços, resolução de problemas, etc..) } & 60,00 \\
\hline \multicolumn{3}{|c|}{ Total de insumos e despesas 45 dias } & 385,80 \\
\hline \multicolumn{3}{|c|}{ Total de insumos e despesas 30 dias } & 257,20 \\
\hline \multicolumn{3}{|l|}{ Sub-total 2} & 638,40 \\
\hline
\end{tabular}

Para que se possa analisar o custo mensal adota-se o custo para trinta dias de produção.

Total de custos (Custo fixo + variável) $=$
$R \$ 638,40+\mathrm{R} \$ 530,36=\mathrm{R} \$ 1.168,76$
Produção total/estufa/mês $=4.000$ cabeças,
sendo que as perdas de cabeças de alface
chegam a $10 \%=3.600$ cabeças aproveitáveis
Receita total = 3.600 cabeças $\times \mathrm{R} \$ 0,50=$
$\mathrm{R} \$ 1.800,00$
$\mathrm{Lucro} /$ estufa/mês $=\mathrm{R} \$ 1.800,00-\mathrm{R} \$ 1.168,76=$
$\mathrm{R} \$ 631,24$
Preço obtido por cabeça de alface vendida $=$
$\mathrm{R} \$ 060$

Custo por cabeça de alface produzida $=\mathrm{R} \$ 0,32$

Lucro por cabeça alface produzida $=\mathrm{R} \$ 0,28$

Lucro para cinco estufas de produção/mês = $\mathrm{R} \$ 3.156,20$
Remuneração do empresário/estufa/mês = $\mathrm{R} \$ 120,00$

Remuneração do empresário/cinco estufas $/$ mês $=R \$ 600,00$

Total de benefícios $/$ mês $=R \$ 3.756,20$

Total de investimentos $=\mathrm{R} \$ 57.000,00$

Lucro anual para cinco estufas $=R \$ 3.756,20 x$ 12 meses $=\mathrm{R} \$ 45.074,40$

Lucro mensal de $50 \%=\mathrm{R} \$ 3.756,20 \times 0,5=$ $\mathrm{R} \$ 1.878,10$ para cobrir o investimento total.

Pagamento do investimento $=\mathrm{R} \$ 1.878,10 \mathrm{x}$ 12 meses $=\mathrm{R} \$ 22.537,20 \times \quad 2,5 \quad$ anos $=$ $\mathrm{R} \$ 56.343,00$

Em dois anos e meio pode-se cobrir o investimento inicial partindo do princípio que $50 \%$ do lucro mensal é convertido em pagamentos (financiamento). 


\section{DISCUSSÃO}

O que pode se considerar em relação à discussão dos resultados seria a viabilidade evidenciada, onde a partir do preço recebido pelo produtor, quase $50 \%$ do mesmo se define como lucro. O pagamento do investimento inicial, se levado a rigor e se a produção se mantiver estável durante o ano, ocorre em torno de 2,5 anos, o que representa um curto prazo, comparado com outras técnicas. O que se evidenciou com este trabalho foi a maior taxa de custo voltada para transporte, aquisição e montagem das estufas, sendo porém, esses dois pontos passíveis de manipulações com a finalidade de diminuir os custos e aumentar o lucro final.

Outro ponto extremamente importante é que o produtor deve utilizar manejo adequado, pois isso não só proporciona o retorno mais rápido do investimento como acelera a estabilidade de mercado do consumidor, tendo em vista um perfeito equilíbrio da produção durante todo o ano, isso devido especialmente à diminuição dos efeitos do ambiente sobre a cultura em hidroponia.

Os insumos não apresentam grande participação relacionada aos custos com a estufa e combustíveis. Isso demonstra que a maior preocupação em minimizar os custos não estaria diretamente relacionada aos insumos e sim na estrutura das estufas, ou seja, pela utilização de materiais construtivos mais baratos e econômicos. Atualmente existem vários tipos de estruturas que se adaptam a diferentes regiões, com custos variando entre $R \$ 1.000,00$ e $R \$ 3.000,00$ com $350 \mathrm{~m}^{2}$ de área, sendo a tecnologia e manejo adequados para os precursores de produtividade e eficiência em cultivo protegido.

O custo de produção obtido por cabeça de alface comercializada foi 0 de $\mathrm{R} \$ 0,32$, preço esse acima dos valores estimados por Faquin et al. (1996) [2] que foi de $\mathrm{R} \$ 0,15$, o que representa uma diferença de $R \$ 0,17$ a mais para o produto comercializado. Martins e Silva (1997) [5] relatam que os custos de implantação de um sistema hidropônico para alface são bastante variáveis, especialmente em função da estrutura utilizada, recomendando que o agricultor utilize materiais e mão-de-obra disponível na propriedade para reduzir o custo da estrutura. O custo de produção está estimado em $R \$ 0,10$ sem considerar a amortização do investimento inicial, o que nesse caso representa diferença de $\mathrm{R} \$ 0,22$ em relação ao custo obtido. Para Furlani (1998) [3], o custo de produção varia entre $R \$ 0,10$ e $R \$ 0,15$, ou seja, esse intervalo representa valores citados por Martins e Silva (1997) [5] e Faquin et al. (1996) [2], respectivamente.

\section{COMENTÁRIOS FINAIS}

1) A hidroponia é um método de cultivo prático que exige atenção quanto ao preparo, controle periódico de $\mathrm{pH}$ e condutividade da solução, bem como cuidados fitossanitários em razão de ataque de insetos e outras pragas, onde higiene e bom manejo das plantas e estufas reduz sensivelmente os problemas.

2) Apesar do custo inicial elevado, em médio prazo se consegue converter 0 investimento em benefícios

3) A produção é contínua em quase todo ano, o que garante boas perspectivas de mercado em relação à entressafra, onde geralmente a demanda é maior pelo produto.

4) A qualidade do produto é alta e sugere bons preços e boa aceitação no mercado, com conseqüente aumento da confiança e demanda do produto.

5) Há muitas vantagens para a produção em pequenas áreas próximas aos centros consumidores em razão da utilização de baixo volume de água e do controle de qualidade da mesma, do uso de pequenas quantidades de fertilizantes, da redução do uso de defensivos, da redução do número de operações durante o ciclo da cultura, da antecipação da colheita, da melhor qualidade e melhores preços dos produtos obtidos, da produção fora de época (sazonalidade), da redução dos riscos provenientes de adversidades climáticas e do rápido retorno econômico.

6) Há poucas desvantagens nessas condições onde o custo inicial é relativamente elevado, exige assistência e conhecimento de técnico efetivo do sistema, há risco de perda por falta de energia elétrica, requer acompanhamento permanente do funcionamento de todo sistema e controle da solução nutritiva.

7) A hidroponia ainda está crescendo e tende a ser a prática alternativa do futuro, pois pode-se produzir grande quantidade de alimentos em pequenas áreas quando comparada ao método convencional.

8) As estruturas utilizadas variam de acordo com as regiões e os custos de implantação, sendo que muitas variáveis tornam-se evidentes como pilares (concreto ou madeira tratada ou madeira sem tratamento), cobertura (arcos de madeira ou ferro ou ferro galvanizado), plástico de polietileno (espessura, aditivado ou não), mercado regional (demanda e oferta do produto), bancada e calhas (diversos materiais), mudas (espuma fenólica ou compra de produtores de mudas ou mudas de sementeiras), uso de defensivos ou não, soluções variadas em concentração, dentre outros fatores.

9) Uma forma de apresentar a melhor estrutura para o cultivo hidropônico de alface nos sistema NFT é pela análise do conjunto de componentes que apresente maior resistência, durabilidade e menor custo, o que poderia ser feito por interpolação de todas essas variáveis.

10)A produção hidropônica pode alcançar bons preços (rápido retorno econômico), melhor desde que seja utilizada para obter produtos sadios, com excelente qualidade e de alto valor nutritivo. 


\section{AGRADECIMENTOS}

Ao Engenheiro Agrônomo, Paulo César Wolff, proprietário da Chácara Acqua Vita, que possibilitou a realização deste trabalho.

\section{REFERÊNCIAS}

[1] BLISKA JÚNIOR, A.; HONÓRIO, S. L. Manua tecnológico: hidroponia. Campinas: UNICAMP, 1996, $28 \mathrm{p}$.

[2] FAQUIN, V.; FURTINI NETO, A. E.; VILELA, L. A. A Produção de alface em hidroponia. Lavras: UFLA, 1996. $50 \mathrm{p}$.
[3] FURLANI, P. R. Instruções para o cultivo de hortaliças de folhas pela técnica hidroponia - NFT. Campinas: Instituto Agronômico, 1998. 30 p. (Boletim Técnico 168).

4 HOFFMANN, R.; SERRANO, O.; NEVES, E. M.; THAME, A. C.; ENGLER, J. J. Administração da empresa agrícola. 5.ed. São Paulo: Pioneira, 1987. $325 \mathrm{p}$.

5 MARTINS, D. E. C.; SILVA, S. E. D. Hidroponia: uma técnica fascinante. Curitiba: D. E. C. Martins, 1997. $62 \mathrm{p}$.

6 RESH. H. M. Cultivos hidropônicos. 4.ed. Madrid: Ed. Mundi-Prensa, 1997. 509 p.

Recebido para publicação em 06 ABR 2000 [SA 020/2000] Aceito para publicação em 24 ABR 2001 